\title{
Radio+ and Open Source Software for Mobilizing Knowledge for Sustainable Agriculture in Sri Lanka
}

Faria Rashid, Helen Hambly, Gordon Gow, Nuwan Waidyanatha, Udith Jayasinghe, Chandana Jayathilake

\section{What this research is about}

- The project established community-university research partnership to explore the potential for low cost Information and communication technologies (ICTS) to enhance knowledge mobilization practices within agricultural communities of practice in Sri Lanka.

\section{What the researchers found}

- Radio+ has the potential to strengthen networks and participatory communication.

- "Radio+" creates strong multi-directional communication relations and multi-media connection between agricultural experts and farmers.

- "Rangiri Radio" converged Free and Open Source Software (FOSS) and broadcast radio to create opportunity for farmers to get involve in radio programs.

- Use of new ICTs and multimedia farm programs creates interests and motivates farmers especially youths to join agricultural knowledge mobilization activities.

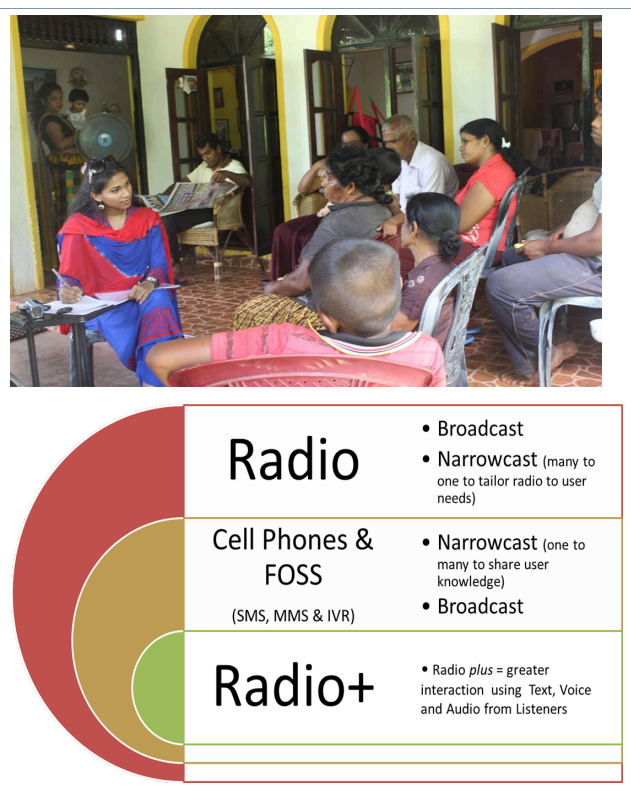

\section{What you need to know}

To know more

Faria Rashid; rashidf@uoguelph.ca

\section{What the researchers did}

- This research was designed to explore how converging emerging ICTs such as Frontline SMS and Freedom Fone with broadcast radio referred to as $\left(\mathrm{Radio}^{+}\right)$can help to mobilize knowledge for sustainable agriculture.

- Researchers used participatory workshops at the community level and discussions with radio stations for data collection.

- Hands-on workshops demonstrated the use of free and open source software (e.g. freedom Fone, Ushahidi and Frontline SMS) to engage with communities about their needs for agricultural information and to share knowledge among farmers, extension workers, scientists and other industry stakeholders.

- Partnership projects in countries such as Sri Lanka can be relevant examples for Ontario. Lessons learned points on how to use ICTs more effectively to mobilize local and expert knowledge for sustainable agriculture. For example, hands-on workshops demonstrates usefulness of new FOSS technologies.

- Radio+ may be a relevant concept in countries like Canada. Researchers should consider programs or policies that builds capacity of the next generation of farmers who may easily use and understand ICT tools. 